\title{
An application of combined geophysical methods to the subsurface investigation in old mine activities area
}

\author{
Ryszard Ślusarczyk \\ University of Mining and Metallurgy AGH \\ Geophysics Department, Krakow, Poland
}

The risk of further subsidence is still present in areas of old mining activities. For a surface protection it is very important to locate dangerous zones connected with old galleries down to a depth of $100 \mathrm{~m}$ below the ground level. Activity up to this depth may produce inhomogenous subsidence of the exploited area overburden. Sinkholes are moving slowly up to the surface and when appears near the earth surface they cause sudden collapse of ground.

The subsurface recognition is especially important in towns, because of old buildings stability and new needs connected with infrastructure and industry development. In the old Polish mining areas, in the overburden of carbon layers appears shoals of Triassic limestones of 20-50 meters thickness which prevent a process of voids expansion into a surface. In the limestone layer above former mine workings, stress can be cumulated, and in special cases such as :

- excessive loading of a ground in a case of high-rise buildings and factories,

- breakdown of water or sewerage systems which can start a process of suffosion;

could overcome the critical values and cause a subsidence of surface.

This type of threat has been a subject researches in the area of old monumental town in Upper Silesia, Poland. 
At the first exploration stage we used the refraction method. The refraction measurements displayed velocity changes along a shallow limestone layer lying above Carboniferous strata (Fig. 1).

We observed wide fractured zone and the subsidence caused by collapsed old galleries and the overburden. When the value of velocity on refraction spread was low (1800-2500m/s) we stated that such area issafe and after subsidence.

Because the faulted zone without mining activity was also in the subsidence area in the next steps we measured seismic reflection (Fig. 2), gravity (Fig. 3) and DC geoelectric line (Fig. 4a,b).

After interpretation of all geophysical, geological and mining data we limited the size of endangered zone and presented a prognosis of the future process of destroying the surface if special steps will not be undertaken.

We proposed special test borehole near church building (Fig. 3) because it is in our opinion - most dangerous area.

\section{REFERENCES}

Marcak H., Ślusarczyk R., 1997 -

Changes in seismic parameters due to fracture development in mine.

European Journal of Environmental and Engineering Geophysics, no. 1.

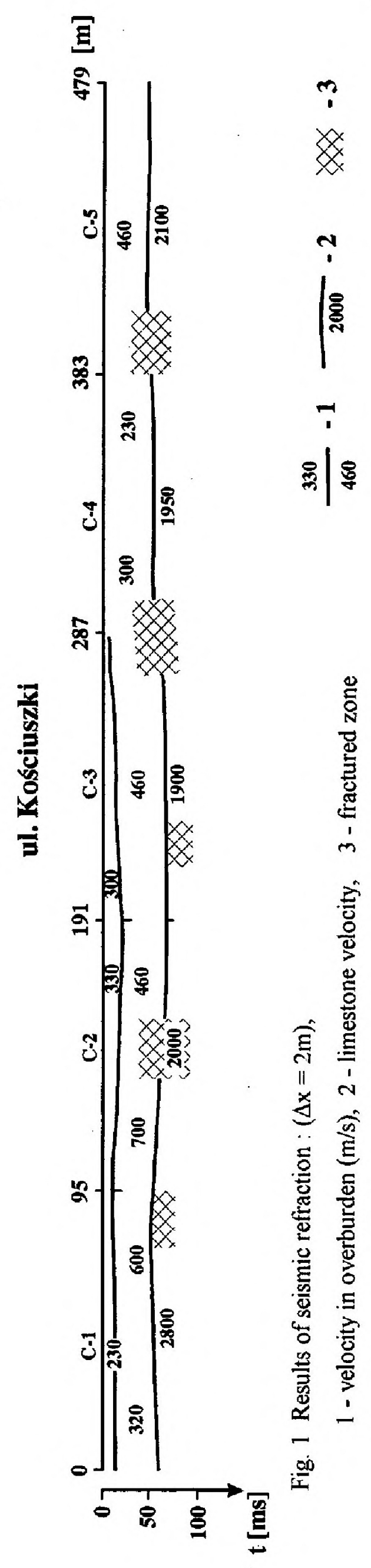


a)

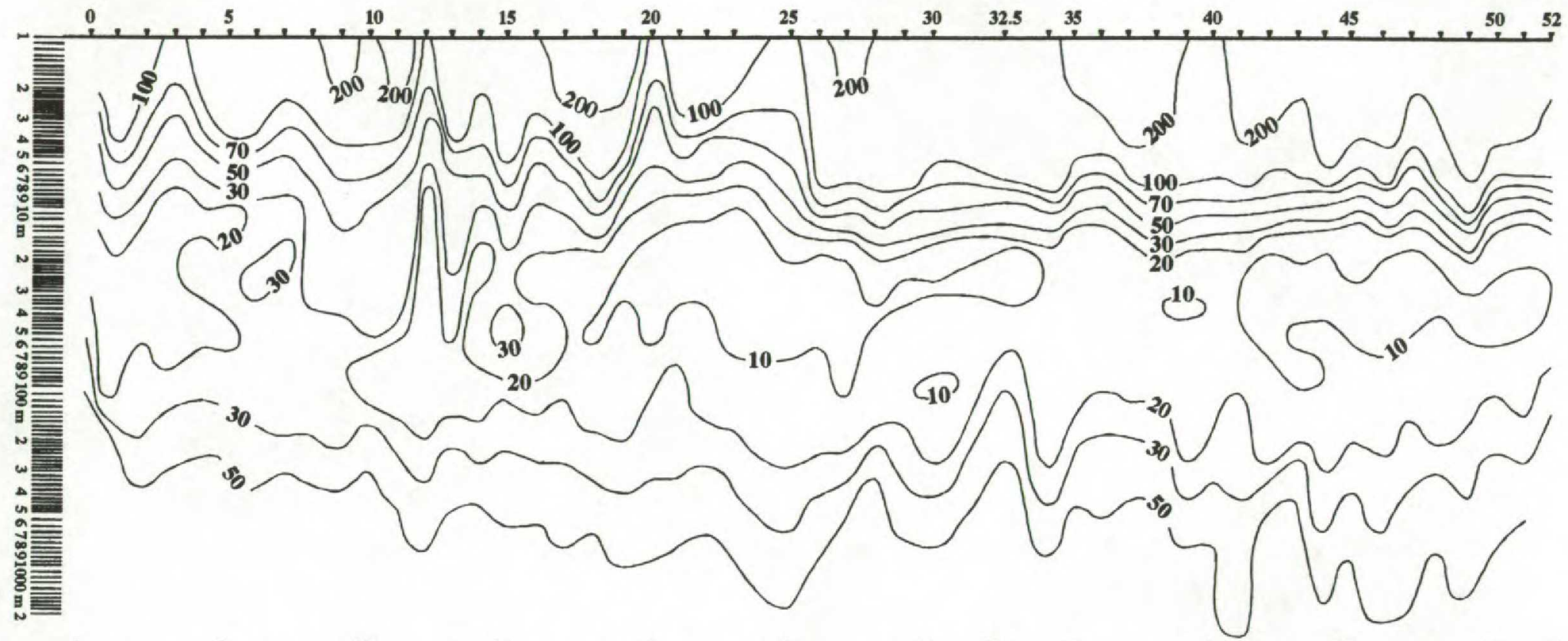

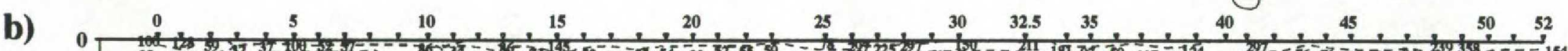

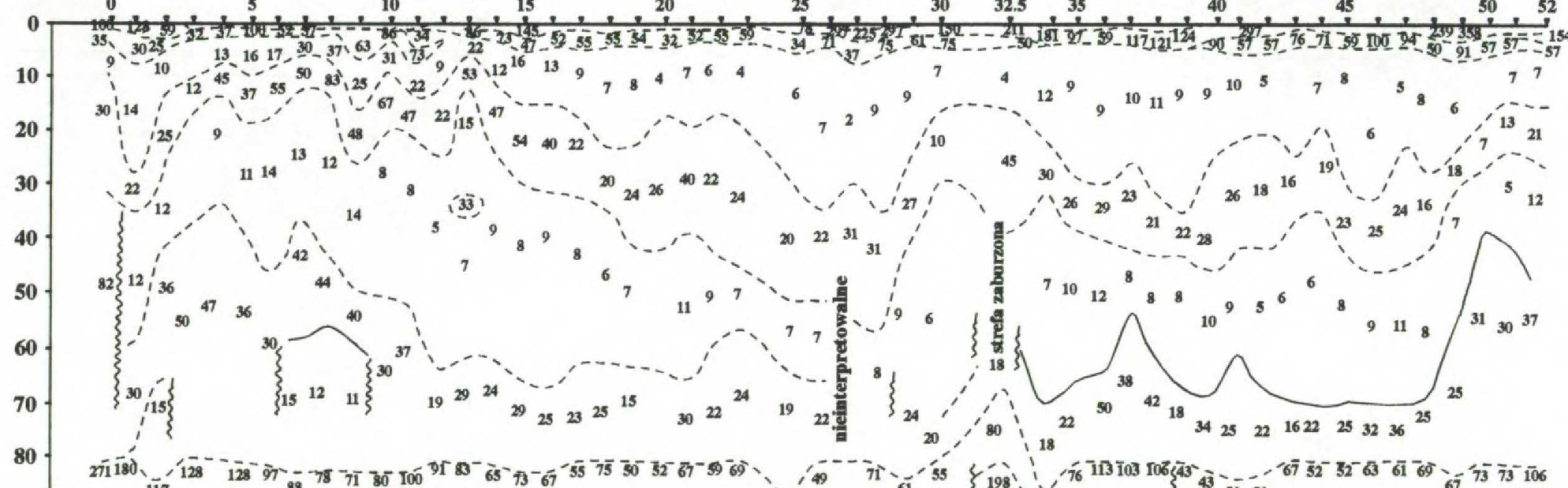

$\mathbf{H}, \mathbf{m}$

Fig. 4. Results of resistivity measurements: a: map of izoohms, b: depth section, $\mathrm{H}(\mathrm{m})$ 


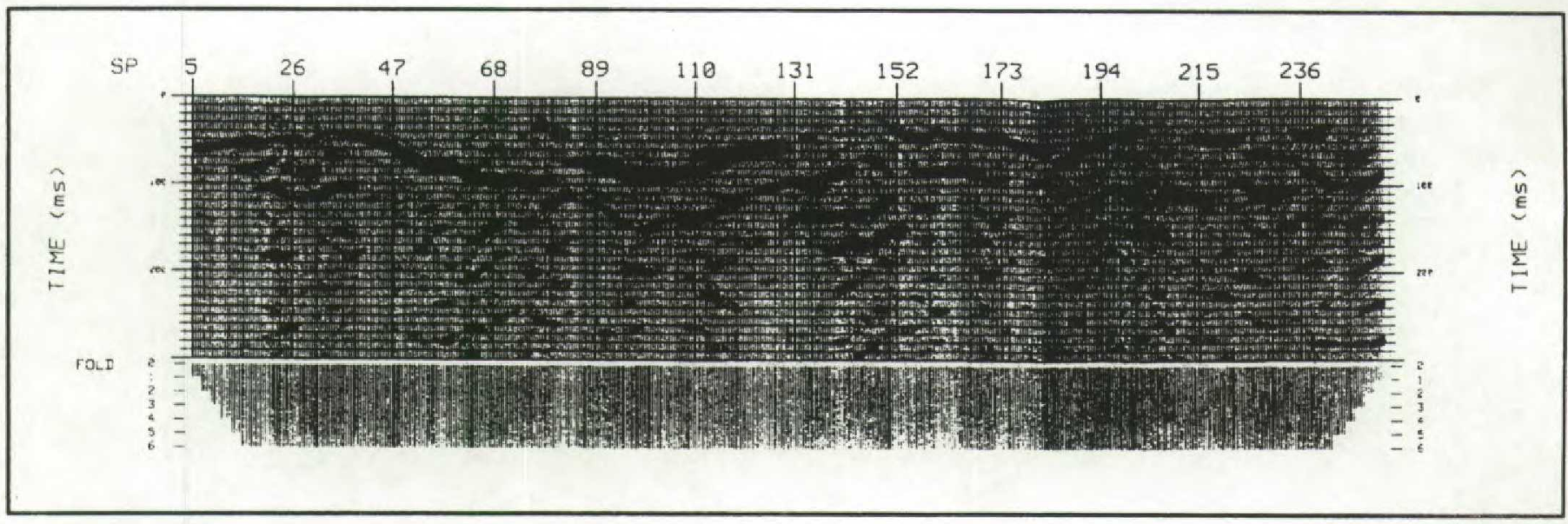

Fig. 2 Seismic reflection time section : $\Delta x=2 \mathrm{~m}, 12 \mathrm{x}$ fold coverage,

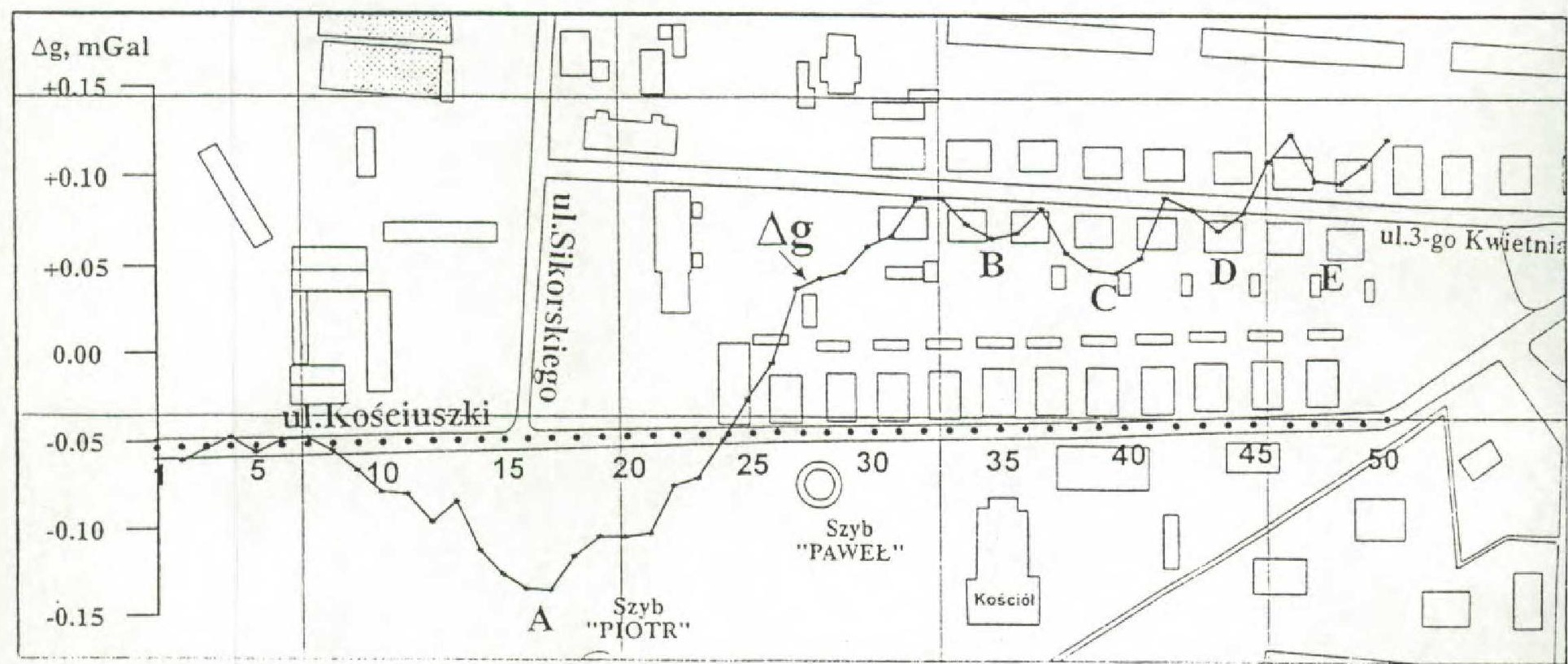

Fig 3. Results of gravity measurements : $\Delta \mathrm{g}$ in $\mathrm{mGal}, \quad 45$ - number of measurement point 